\title{
CARMEN: LA CONSTRUCCIÓN DEL TEXTO Y DEL MITO ESPAÑOL A PARTIR DEL TÓPICO DE UN VIAJERO ROMÁNTICO FRANCÉS
}

\author{
Miguel Ángel Muro Munilla* \\ Universidad de La Rioja \\ Para Carmen... \\ Cunchillos
}

\begin{abstract}
RESUMEN: Este artículo se acerca al mito de Carmen para considerar su estructura, enmarcada y mixta entre ficción y ensayo erudito, valorándola como acertada estéticamente, al entenderla como propia de la mirada topificadora y erudita de un viajero francés del siglo XIX sobre lo español costumbrista y sobre los gitanos, en particular; mundo en el que la muerte violenta zanjaba los asuntos de amor y celos y bajo el que laten los mitos antiguos de la mujer como fuerza maléfica.

ABSTRACT: This article approaches Carmen's myth to consider his structure, framed and mixed between fiction and erudite essay, valuing it like succeeded aesthetically, on having understood it like proper of the topic and the erudition of a French traveler of the XIXth century on Spanish writer of folk literature and on the gypsies, in particular; world in which the violent death was settling the matters of love and jealousy and under which there beat the ancient myths of the woman as harmful force.
\end{abstract}

PALABRAS CLAVE: Gitanos, mito, tópico, viajero.

KEYWORDS: Gypsies, myths, topic, traveler.

* El autor pertenece al Centro de Investigación en Lenguas Aplicadas (CILAP) de la Universidad de La Rioja. 
El 28 de abril de 1843 estrenaba Bretón de los Herreros Un francés en Cartagena, una divertida sátira contra los tópicos desatinados que los viajeros franceses iban vertiendo en sus libros sobre España. En ella, un muchacho francés comete numerosas estupideces guiado por su voluntad de agradar a sus huéspedes, pero mal orientado por sus lecturas de libros de viajeros franceses. En el desenlace, ya todos los personajes hartos de desencuentros, el padre de la muchacha española con la que venía a casarse pronuncia un discurso casero contra aquellos libros; dice don Cipriano:

\author{
¡Ya se ve, \\ dama española y navaja \\ bajo la liga, es de ley! \\ ¡Y aquí todos son toreros \\ y gente de ese jaez; \\ y en cada casa hay un fraile \\ que nos manda como rey; \\ y en las artes y en las ciencias \\ vamos con el siglo diez; \\ y empieza en los Pirineos \\ el territorio de Argel! \\ Hay en España infinidad \\ de españoles que dan fe \\ de lo contrario; no importa: \\ Nadie -responden- es juez \\ competente en propia causa, \\ ¡Y sólo es pintura fiel \\ de España la que ellos fingen \\ como Dios les da a entender! \\ $\mathrm{Y}$ escriben de nuestras cosas \\ veinte folletos al mes; \\ mas, si una vez en el clavo, \\ dan en la herradura cien; \\ que contraen cataratas \\ cuando aquí ponen el pie \\ para ver ... lo que no miran \\ y mirar lo que no ven. \\ Así, la excepción es regla \\ para ellos, y tal vez \\ si en hora menguada a alguno \\ muerde en la calle un lebrel, \\ con mucha formalidad \\ nos dirá luego Gautier: \\ «Todos los perros de España \\ muerden... entre cinco y seis». \\ $\mathrm{Y}$ no faltan escritores
}




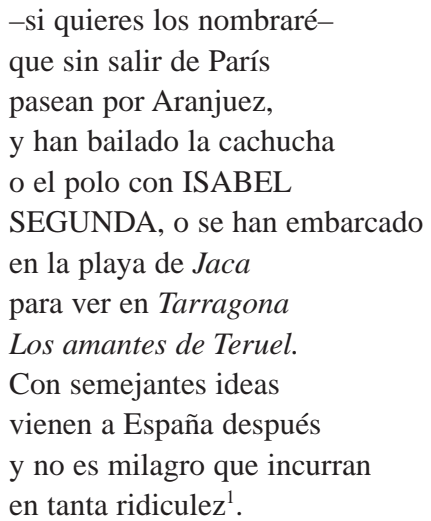

Dos años después, en 1845, se publicaba Carmen, y aunque el parlamento satírico no carece de razón al señalar los peligros del tópico, no cabe duda de que su utilización puede dar lugar a textos deleznables, pero también a obras de gran interés, como la de Mérimée.

«En voyage il faut tout voir ${ }^{2} »$, «En los viajes hay que verlo todo», manifiesta el autor-narrador ${ }^{3}$ de Carmen, Próspero Mérimée, cuando relata su encuentro con «Carmencita» en un atardecer cordobés y su decisión de mantener la invitación a tomar un helado que acaba de hacerle a la muchacha, aunque también acaba de saber que es gitana. La novela-libro de viajes ha comenzado, pocas páginas antes, con el relato del encuentro del erudito con D. José, salteador de caminos y -reflexiona el francés- a ello va a sumar el trato con «una fámula del diablo». Se van presentando y aproximando así los tres actores principales del poderoso mito moderno de Carmen, con la peculiaridad de que el viajero-narrador a quien se debe el texto va quedando fuera de la historia para dejar en ella a sus protagonistas dramáticos. Y es que en relación con Carmen se produce el hecho curioso (aunque no único: depende de memorias) de que se olvide con frecuencia (o directamente, se desconozca) que se trata de una historia enmarcada,

1. Manuel Bretón de los Herreros, «Un francés en Cartagena», en Teatro Breve, vol. II. Estudio introductorio y edición de Miguel Ángel Muro. Logroño: Universidad de La Rioja, 2000, pp. 279-280.

2. Las citas en francés se harán de Prosper Mérimée, Carmen et autres histories d'Espagne. Preface et commentaires de Pascaline Mourier-Casile, Pocket, 1990. Las traducciones se harán siguiendo a Mérimée, P., Carmen. Edición de Luis López Jiménez y Luis-Eduardo López Esteve. Madrid: Cátedra, 1997.

3. García Landa, J.A. (1998): Acción, relato, discurso. Estructura de la ficción narrativa. Salamanca: Ediciones Universidad de Salamanca, p. 322; Muro, M.A., Análisis e interpretación del cómic. Ensayo de metodología semiótica. Logroño: Universidad de La Rioja, 2004, pp. 145-147. 
de un relato de segundo nivel ${ }^{4}$, que comienza con Mérimée convertido en viajero erudito que viaja a España en busca de la localización exacta de la batalla de César contra los hijos de Pompeyo, en Munda, si bien, como ocurre con otros tantos de sus compatriotas, el viaje deriva pronto hacia la querencia del tipismo y del tópico español. El libro se cerrará con un capítulo erudito, en el que Mérimée expone el resultado de sus investigaciones sobre los gitanos y su lengua.

La estructura de Carmen (mixta entre ficción y ensayo erudito) viene siendo objeto de controversia entre quienes la consideran adecuada y quienes deploran la inclusión del último capítulo, un breve ensayo erudito sobre los gitanos. Carmen -a mi modo de ver- es un texto confeccionado con materiales heterogéneos que dan lugar a una estructura desequilibrada ${ }^{5}$ que resulta ser muy eficaz, lo mismo que el hecho de que la relación central de la obra se lleve a un cuerpo a cuerpo, casi teatral, casi de ballet, entre D. José y Carmen, viene a posibilitar una condensación propia de lo teatral ${ }^{6}$ y del relato breve. Los dos primeros capítulos, por su parte, cumplen la función de poner en escena al viajero-narrador y a los dos personajes principales del drama. El último, por su parte, se vincula por su información con los anteriores, para construir el todo conjunto decidido por el autor.

La inclusión del autor-narrador en la trama del relato tendría que conferirle a éste la condición testimonial propia de buena parte de los libros de viajes, de autobiografías o de memorias de distinta índole y, de hecho, eso es lo que se va transmitiendo al lector en los dos primeros y breves capítulos en los que se encuentra y roza con D. José y Carmen. Pero en Carmen el papel principal que el Mérimée introducido en la ficción se reserva para sí es, sobre todo, el de atento oyente de «las tristes aventuras» de aquellos; papel de confidente que viene a derivarse del papel del viajero que busca y encuentra, halagado, el contacto con estas figuras supuestamente representativas de lo español: testigo y algo partícipe de la trama, primero, y confidente después. A tal fin, el encuentro con D. José sirve para presentar a este protagonista, para que el francés se haga acreedor a su confianza y

4. Genette, G., Figures III. Paris: Seuil, 1972, pp. 238-243; Genette, G., Nuevo discurso del relato. Madrid: Cátedra, pp. 55-64; Rimmon Kenan, S., "A Comprehensive Theory of Narrative: Genette's Figures III and the structuralist study of fiction", Poetics and Theory of Literature, I, 1976, pp. 33-62; Lanser, S., The narrative act. Point of view in fiction. Princeton: Princeton U.Press, 1981.

5. Tomasesvki, B., Teoría de la literatura. Madrid, Akal (Trad. de Teorija literatury Poetika. Leningrado, 1925), pp. 258-260.

6. Ubersfeld, A., Semiótica teatral. Madrid, Cátedra- Universidad de Murcia, 1993; Greimas, A.J., «Hacia una teoría del discurso poético», en Greimas, A.J. y otros: Ensayos de semiótica poética. Conjunto dirigido por A.J.Greimas. Barcelona: Planeta, 1976, Muro, op. cit., pp. 203-206. 
respeto y, en relación con el color local, para que el viajero se alegre por poder estar al lado de un bandolero famoso y peligroso; el encuentro con Carmen tiene como finalidad presentar a la muchacha, entrar en contacto con ella y con la pareja y sus turbulencias y, además, -como motivo muy funcional- para propiciar que Carmen le robe el reloj por el que después entrará en contacto con don José, ya condenado a muerte, quien lo considerará el oyente adecuado para escuchar la historia central, la del drama pasional. En el tercer capítulo, es ya D. José quien se convierte en narrador de la historia de la que es protagonista y Mérimée quien escucha atentamente, con tanta discreción... que casi se borra del relato, que de ese modo adquiere una autonomía tan acusada que pasa a funcionar en el recuerdo de los lectores o en las decisiones de los adaptadores como un relato exento. De hecho, el final del relato hecho por D. José viene a ser el final ficcional del texto, sin que su oyente y narrador principal vuelva a tomar las riendas de la narración para recuperar el nivel inicial enmarcante. El cuarto y último capítulo del texto se despreocupa de cualquier ficcionalidad para constituirse en un artículo erudito que tiene como objeto mostrar a los lectores de Carmen el conocimiento que Mérimée tiene de los gitanos y, en particular, del romañí, su lengua: uno de los motivos del texto de ficción, el mundo de los gitanos, pasa a convertirse así en el asunto que cierra el libro, fuera ya de la ficción y -podría decirse-, sin relación alguna con el viaje, cuando menos sin relación con ese Macguffin que resulta ser la búsqueda del emplazamiento de la batalla de Munda.

Y, sin embargo, aunque la enmarcación del texto central no sea equilibrada, el relato de D. José pueda funcionar -y funcione, de hecho, como autónomo- y el capítulo final pueda presentar la apariencia de añadido, de cuerpo extraño, no puede dejarse de lado que esa fue la disposición y forma definitiva que decidió su autor, quien, en buena medida está respondiendo a criterios estéticos y compositivos del XIX romántico, con una concepción del relato mixta de realidad, ficción y erudición o, de otro modo, de libro de viajes, relato de aventuras y texto erudito. La coherencia y cohesión necesarias para la configuración de todo texto artístico son distintas a las más generalizadas, pero no por ello insólitas, ni en su época ni en tiempos más recientes: baste recordar textos híbridos de la literatura actual como los de Ferlosio, Pitol o Fogwill.

De hecho, considero que si se atiende a la configuración de la obra tal como la propuso su autor y se repara en los elementos de cohesión que funcionan en el texto, se produce una iluminación más adecuada del relato central que si éste se lee como autónomo. Por precisar algo más, puede plantearse que la índole de ese relato central se contempla mejor desde el marco del viajero francés prejuiciante de una España tópica que, a su vez, ofrece a sus lectores una estampa dramática 
pasional, ficcional, relacionada directa y estrechamente con sus estudios y escritos de tipo erudito y no ficcional. Y en otra dirección, el relato ficcional viene a vivificar desde su dramatismo el material consignado en escritos del propio autor, como sus Lettres d'Espagne.

Es muy posible que la deriva constante y continua hacia el melodrama pasional que se puede observar en la literatura y los pasatiempos ficcionales españoles desde el siglo XIX hasta bien avanzado el siglo $\mathrm{XX}^{7}$, desdibujen en alguna medida el hecho de que el mito de Carmen, de apariencia tan española, proviene de la mirada topificadora de un viajero, erudito y escritor francés, movida por el interés que el romanticismo burgués mostró por el costumbrismo castizo y por el exotismo; en el primero se buscaban las raíces de los pueblos, en una noción paradójica, a la vez idealista y fuertemente localizada en el tiempo específico de la época; con el segundo se pretendía dotar a la burguesía de mundos que ampliaran sus horizontes vitales; si satisfechos, como pasatiempo inocuo, como evasión; si inconformistas, como lenitivos o utopías.

El brioso alegato de reafirmación patriótica de la copla española, «Carmen de España», percute contra la visión foránea de Mérimée, en pleno rearme nacionalista de la dictadura franquista y en la activación de coros y danzas regionales, de la Sección Femenina, del culto institucional a la Virgen del Pilar (que tampoco quería ser francesa), y hasta del D. Pelayo que iluminaba la segunda cruzada española, lo mismo contra moros que contra todo lo que no fuera genuinamente español.

El texto de Quintero y León, con música de Quiroga de 1953, subrayaba de forma pendenciera la ofensa que suponía para la mujer española el tipo pergeñado por Mérimée, al que la Carmen de España de la copla «haría en pepitoria/ si volviera aquí otra vez». Y es que el viajero, desde su foraneidad y su condición de francés, habría cometido el desafuero de concebir una mujer española -aunque fuese gitana-, pagana e indecente, frente al prototipo de la religiosidad y honestidad,

7. Sánchez Salas, D., Historias de luz y papel. El cine español de los años veinte, a través de su adaptación de narrativa literaria española. Murcia: Filmoteca Regional, 2007, pp. 321-327 y 418. Antes y después del cine, porque, como constataba Ramón Pérez de Ayala sobre el teatro y el cine, en 1927: «Antes del advenimiento del cinematógrafo, la diversión favorita de esas barriadas plebeyas era el melodrama truculento y de gran espectáculo. Este melodrama se reputaba no menos antagonista con aquello que los intelectuales y artistas entienden por verdadero teatro, que el actual cinematógrafo». («La crisis teatral», 1917-1919, p. 538, en Javier Huerta Calvo, dir. Historia del teatro español. II. Del siglo XVIII a la época actual. Madrid: Gredos, 2003, p. 2250). 
incuestionables, de sus mujeres, vistas desde la ideología española ${ }^{8}$. De hecho, el referente prestigioso más próximo que podía tener Carmen en la literatura española era La gitanilla de Cervantes, y en ella quedaba a salvo cualquier atentado contra la moralidad, porque, si bien Preciosa es de una desenvoltura chispeante en el toma y daca con los hombres, en todo momento el narrador deja claro (hasta en exceso) que su honestidad está fuera de cuestión: sus cantares y su comportamiento han de ser honestos y su virginidad es la única joya que posee ${ }^{9}$; algo que el narrador cervantino achaca a que, en realidad, no era gitana -en claro menoscabo de los gitanos.

Y es que es en la condición de gitana de Carmen donde Mérimée pone el acento y donde hace estribar los rasgos que, a la postre, iban a dar como resultado esta configuración moderna del mito de la mujer fatal. El viajero que acude a España en busca de lo peculiar, de lo genuino de este país, actúa extremando los rasgos del costumbrista, actuando por reducción. Si buena parte del costumbrismo español se caracteriza tanto por reflejar las costumbres de la época, como por fijar aquellos tipos y usos que podían perderse y, como en los aguafuertes, por atender a lo más llamativo (que no a lo más definitorio o sustancial; es el caso, por ejemplo, de Sera-

8.

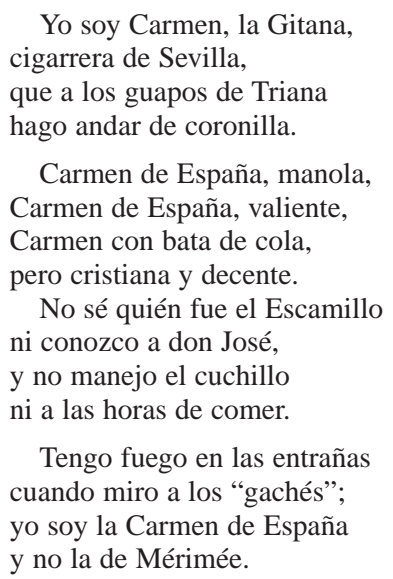

9. «Una sola joya tengo, que la estimo en más que a la vida, que es la de mi entereza y virginidad, y no la tengo de vender a precio de promesa ni dádivas, porque, en fin, será vendida, y si puede ser comprada, será de muy poca estima; ni me la han de llevar trazas ni embelecos: antes pienso irme con ella a la sepultura, y quizá al cielo, que ponerla en peligro que quimeras y fantasías soñada la embistan o manoseen. Flor es la de virginidad que, a ser posible, aun con la imaginación no había de dejar ofenderse. Cortada la rosa del rosal, ¡con qué brevedad y facilidad se marchita! Éste la toca, aquél la huele, el otro la deshoja, y, finalmente, entre las manos rústicas se deshace. Si vos, señor, por sola esta prende venís, no la habéis de llevar sino atada con las ligaduras y lazos del matrimonio; que si la virginidad se ha de inclinar, ha de ser a este santo yugo; que entonces no será perderla, sino emplearla en ferias que felices ganancias promete». (Cervantes, Miguel de, La gitanilla. La ilustre fregona, Madrid: Espasa-Calpe, 2003, p. 35). 
fín Estébanez Calderón, buen amigo de Mérimée), no es de extrañar que la mirada foránea quede prendada también del trazo fuerte social, de lo llamativo. De este modo, el relato del viajero erudito tarda muy poco en derivarse hacia su verdadero cometido que es encontrarse con gitanos, bandoleros, contrabandistas o toreros y contar de ellos; gentes al margen de la sociedad que engañan, asaltan, trafican, pelean a navaja y saldan sus diferencias con la violencia: materia emocionante para el francés. Este mundo costumbrista y castizo ${ }^{10}$ es el mundo que le interesa al viajero romántico Mérimée, mundo para el que ya tenía antecedentes, algo remotos -como ya dijimos- en el caso de La gitanilla ${ }^{11}$, y cercanos, por ejemplo, en Nuestra Señora de París, de Víctor Hugo, publicada en 1831.

La comunidad tópica sobre los gitanos -y sobre la mujer gitana, en particulares notable en estos textos: la leyenda negativa sobre los gitanos está presente en todos ellos, desde el arranque infamante de Cervantes, considerándolos intrínsecamente ladrones ${ }^{12}$, al capítulo final de Carmen, donde se habla de su trato con las drogas, y su familiaridad con el demonio, la fealdad de las gitanas españolas y su tremenda suciedad, pasando por la repetición del tópico de los gitanos ladrones de niños y sectarios del diablo que actúa como factor primordial en la trama de la obra de Hugo. Nuestra Señora de París es sin duda el relato que activa de forma más simple el tópico, sin matices, sin complejidad alguna ${ }^{13}$, aunque, al final, tampoco Esme-

10. Uno de los personajes de Lo cursi (1901), de Jacinto Benavente, describe con contundencia qué se entiende por «casticismo»: «Sí; en literatura ya sé en qué consiste: en lo que ustedes llaman vigor; en concluir los dramas a tiros, y las cuentas a navajazos; como si todos los días se recogieran cadáveres por esas calles. Para usted, querido marqués, sé también en qué consiste el casticismo: en estar abonado a los toros y en comer judías estofadas en casa de la Concha." (Benavente, J., Obras completas, I, Madrid: Aguilar, 1969, pp. 603-604).

11. Más lejano todavía quedaba El paso de la Gitana y Gargullo, de Lope de Rueda, con un personaje-tipo caracterizado ya como echadora de la buenaventura y ladrona. (vid. José Luis Canet, «Lope de Rueda y el teatro profano», en Historia del teatro español I. De la Edad Media a los Siglos de Oro. Javier Huerta Calvo (Director). Abraham Madroñal Duran y Héctor Urzáiz Tortajada (coord..). Madrid: Gredos, vol, I, 2003, p. 463).

12. «Parece que los gitanos y gitanas solamente nacieron en el mundo para ser ladrones: nacen de padres ladrones, críanse con ladrones, estudian para ladrones y, finalmente, salen con ser ladrones corrientes y molientes a todo ruedo; y la gana del hurtar y el hurtar son en ellos como acidentes inseparables, que no se quitan sino con la muerte». (Miguel de Cervantes, op. cit., p. 11).

13. «Eran pícaros auténticos; truhanes que iban recorriendo el país, llevados por su duque y por sus condes. Eran cetrinos y tenían el pelo muy rizado y aros de plata en las orejas. Las mujeres eran aún más feas que los hombres. [...] Era una verdadera banda de canallas que venía derecha desde el bajo Egipto hasta Reims, atravesando Polonia. [...] Había muchos rumores sobre ellos como el de ser ladrones de niños y de dinero y el de comer carne humana. [...] La noche que acababa de pasar era precisamente la del sábado y ya nadie puso en duda que los egipcios habían celebrado aquelarre entre aquellos brezos y que habían incluso devorado a la niña en compañía de Belcebú, como es costumbre entre los mahometanos». (Hugo, V., Nuestra Señora de París. Edición de Eloy González Miguel. Traducción de María Amor Hoyos Ruiz y Eloy González Miguel, Madrid: Cátedra, 1985, pp. 243-246). 
ralda sea una gitana verdadera, sino una niña raptada por los gitanos, como Preciosa en la novela de Cervantes; frente a ella, las otras dos muestran algún mayor interés por el mundo al que se refieren y muestran también otros aspectos de los gitanos. En el caso de La gitanilla son notables las páginas en que Cervantes hace hablar a un viejo gitano para que haga profesión de la ideología de sus gentes, que supone un canto a la libertad, tanto en la vida al aire libre, sin sujeción, como, y sobre todo, en lo relativo a la elección de cónyuge o de amigo y al respeto mutuo, con la advertencia de que la traición se castiga con la muerte afrentosa de la infiel, con lo que ya hace aparición el motivo de la muerte violenta, consustancial al mito de Carmen $^{14}$. Lo dicho por el narrador se equilibra dialécticamente con la mostración de los actos de los gitanos (a quienes quiere y respeta Preciosa) y con este parlamento del «elocuente» anciano que, por otro lado, tiene su mucho de ironía ${ }^{15}$. En el caso de Carmen se destacan, desde dentro del texto de ficción y en el capítulo erudito, la altanería de los gitanos frente a otras razas, la solidaridad entre sus miembros y, en particular, la abnegación de las mujeres en el cuidado de sus maridos ${ }^{16}$.

14. «Esta muchacha, que es la flor y la nata de toda la hermosura de las gitanas que sabemos que viven en España, te la entregamos, ya por esposa, o ya por amiga, que en esto puedes hacer lo que fuere más de tu gusto, porque la libre y ancha vida nuestra no está sujeta a melindres ni a muchas ceremonias. Mírala bien, y mira si te agrada, o si ves en ella alguna cosa que te descontente; y si la ves, escoge entre las doncellas que aquí están la que más te contentare; que la que escogieres te daremos; pero has de saber que una vez escogida, no la has de dejar por otra, ni te has de empachar ni entremeter, ni con las casadas, ni con las doncellas. Nosotros guardamos inviolablemente la ley de la amistad: ninguno solicita la prenda del otro; libres vivimos de la amarga pestilencia de los celos. Entre nosotros, aunque hay muchos incestos, no hay ningún adulterio; y cuando le hay en la mujer propia, o alguna bellaquería en la amiga, no vamos a la justicia a pedir castigo; nosotros mismos somos los jueces y los verdugos de nuestras esposas o amigas; con la misma facilidad las matamos y las enterramos por las montañas y desiertos como si fueran animales nocivos; no hay pariente que las vengue, ni padres que nos pidan su muerte. Con este temor y miedo ellas procuran ser castas, y nosotros, como ya he dicho, vivimos seguros. Pocas cosas tenemos que no sean comunes a todos, excepto la mujer o la amiga, que queremos que cada una sea del que le cupo en suerte». (Cervantes, op. cit., pp. 52-53).

15. «Del sí al no no hacemos diferencia cuando nos conviene: siempre nos preciamos más de mártires que de confesores. Para nosotros se crían las bestias de carga en los campos y se cortan las faldriqueras en las ciudades. No hay águila, ni ninguna otra ave de rapiña, que más presto se abalance a la presa que se le ofrece, que nosotros nos abalanzamos a las ocasiones que algún interés nos señalen; y, finalmente, tenemos muchas habilidades que felice fin nos prometen; porque en la cárcel cantamos, en el potro callamos, de día trabajamos y de noche hurtamos; o, por mejor decir, avisamos que nadie viva descuidado de mirar dónde pone su hacienda». (Id., p. 54).

16. «Quoi qu'il en soit, il est certain que les Gitanas montren à leurs maris un dévouement extraordinaire. Il n'y a pas de danger ni de misères qu'elles ne bravent pour les secourir en leurs nécessités. Un des noms qui se donnent les Bohémiens, Romé ou les époux me paraît attester le respect de la race pour l'état de mariage». (Mérimée, 1990, op. cit., p. 97) («Sea lo que fuere, es cierto que las gitanas muestran una abnegación extraordinaria por sus maridos. No hay peligro ni calamidades que no desafíen por socorrerles en sus necesidades. Uno de los nombres que los gitanos se dan, romé o los esposos, me parece que atestigua el respeto de la raza por el estado de casado».) (Mérimée, op. cit., 1997, p. 184). 
Sin embargo, la singularidad de Mérimée frente a estos dos textos de referencia es notable. El viajero romántico se decanta por presentar una verdadera gitana, frente a Preciosa y Esmeralda, que, respondiendo al tópico literario (o al mecanismo de la «novela familiar» descrito por el psicoanálisis ${ }^{17}$ ), no son gitanas, sino muchachas raptadas por gitanos y educadas como tales, aunque las elevadas prendas del personaje cervantino estén dejando atisbar su verdadero origen (tópico literario y social, mediantes), y el planteamiento folletinesco del de Hugo también sea orientador en este sentido hacia la anagnórisis final que aparta a Esmeralda de los gitanos. No obstante, la adjetivación «verdadera» no es la más adecuada para aplicársela a Carmen, ya que el autor-narrador se mueve en la ambigüedad y señala sus dudas respecto a que la joven fuera «de raza pura» ( «Je doute fort que mademoiselle Carmen fût de race pure» ${ }^{18}$ ), aunque la razón para ello sea un detalle de coherencia entre la ficción y la erudición del investigador, y es que, como escribirá en el último capítulo, las gitanas españolas eran más bien feas y Carmen una muchacha muy atractiva. La necesidad de una protagonista femenina seductora y fatal precisaba de este matiz para el autor y para el autor-narrador; como es interesante también que no la describa como un prodigio de belleza a la manera del canon griego, sino que se guíe por el romántico para señalar que «à chaque défaut elle réunissait une qualité qui ressortait peut-être plus fortement par le contraste» ${ }^{19}$.

Mucha mayor novedad y originalidad literarias tiene el hecho de que Mérimée desactive en Carmen el rasgo de honestidad de las otras dos heroínas (inmarcesible en Preciosa y algo menos inamovible en Esmeralda, a punto de claudicar ante la solicitud apasionada del apolíneo Febo), para presentar una muchacha activa erótica y sexualmente, al tiempo que de una libertad irrenunciable frente a los hombres; actitud y comportamiento poco aptos para machistas, sin lugar a dudas. En el capítulo erudito con que cierra su obra, Mérimée discute la apreciación de George Borrow sobre la falta de interés de las mujeres gitanas por hombres extraños a su raza: «Il me semble qu'il y a beaucoup d'exagération dans les éloges qu'il accorde à leur chasteté» ${ }^{20}$. Esta forma de ver las cosas lleva a Mérimée a convertir a Carmen en una clamorosa excepción a la única gran virtud que reconoce en los gitanos, la fidelidad entre los esposos, a la que aludíamos más arriba. Llamativamente, con

17. Otto Rank, El mito del nacimiento del héroe, Barcelona, Paidos, 1981.

18. Mérimée, 1990, op. cit., p. 46.

19. Mérimée, 1990, op. cit., p. 96 («por cada defecto reunía una cualidad que sobresalía quizá con más fuerza por el contraste»., Mérimée, 1997, op. cit., p. 47).

20. Mérimée, 1990, op. cit., p. 96 («Me parece -dice- que hay mucha exageración en los elogios que hace de su castidad»., Mérimée, 1997, op. cit., pp. 183-184). 
quien Carmen tendrá un comportamiento abnegado será con José, cuando es herido gravemente por la tropa, ocultándolo y cuidándolo «elle me soigna avec une adresse et des attentions que jamais femme n'a eues pour l'homme le plus aimé» ${ }^{21}$.

La apreciación despreciativa con que Saint-Beuve despachó la obra de Mérimée cuando fue publicada, «otra Manon Lescaut», es decir, otra prostituta, no suponía sino coger el rábano por las hojas: si las dos protagonistas coincidían en su libertad sexual, desligada del amor y opuesta a la fidelidad a un solo hombre, a ningún hombre ${ }^{22}$, su extracción social («común», en el caso de Manón, marginal en el de Carmen), carácter (agradable en aquella, arisco y hasta violento, en ésta), motivaciones (el placer ante todo, en la francesa, la libertad, en la española), objetivos y comportamiento eran muy diferentes; además, estaban insertas en tramas muy distintas y con función dispar: la obra de Prevost, del 1733, intentaba reflejar la crisis moral de la clase dirigente en la época de la Regencia, tras la muerte de Luis XIV, mientras la de Mérimée ponía en pie una España tópica, romántica en el color local y el peso dado a lo pasional.

Los parecidos entre el caballero Des Grieux y don José, los dos protagonistas masculinos, no van tampoco más allá de la coincidencia en ser arrebatados ambos por la pasión, cuando son jóvenes inmaduros e inexpertos; en ambos también hay una asunción voluntaria de degradación moral y social para poder estar al lado de sus infieles amantes: el engaño y las trampas en el juego, en el caso del francés, el contrabando y el bandolerismo, en el caso del español; pero, además de que don José, de carácter violento (frente al apacible del Caballero), llega al asesinato y a matar él mismo a su amante, la actitud moral de ambos es muy distinta ya que don José mantiene conciencia clara de lo recto y se juzga duramente desde esa conciencia, mientras que Des Grieux se instala pronto en un cinismo de libertino que sólo abandonará con la muerte de Manon, para volver al camino de la virtud y dar con ello razón de ser al «exemplum»: a la postre, el amor es en la obra de Prevost una fuerza redentora, mientras que en la de Mérimée es destructiva; mezclados, además, como están en ambas obras amor y deseo sexual y afán de posesión de la mujer, la proporción de estos componentes también es muy distinta: irían en este orden de importancia para Des Grieux, mientras que se invertirían en el caso de José.

21. Merimée, 1990, op. cit., p. 87, («con una destreza y unas atenciones que jamás ha tenido una mujer para con el hombre más querido»., Mérimée, 1990, op. cit., p. 173).

22. Hablar de inmoralidad o amoralidad afectiva y sexual en la actualidad para describir a estas protagonistas femeninas, no sería sino juzgarlas desde una clara postura ética y religiosa de signo masculino, cuando no machista. 
También responde a las condiciones que el erudito había podido observar en su estudio sobre los gitanos otro de los rasgos con que dota al personaje de Carmen, como es el de «hechicera». La ambigüedad del término se mantiene a lo largo del relato, en la linde entre el significado metafórico de mujer seductora y el de mujer que practica la hechicería, bruja ${ }^{23}$. En el primer encuentro del viajero con la muchacha, el autor-narrador traduce de forma metonímica «bohémienne», «gitana», por «sorcière» «hechicera» y de inmediato por «servante du diable», «fámula del diablo», ante la que, sin embargo, no se arredra cuando le propone leerle la bají porque él -dice- era un incrédulo por aquel entonces («j'étais alors un tel mécréant $\gg^{24}$ ). De hecho, la razón que el narrador aduce para justificar su decisión de estar con ella es su interés por las ciencias ocultas, aunque, experto, pronto concluye, «por su manera de obrar» que «il était évident qu'elle n'était pas sorcière á demie» ${ }^{25}$. Y sin embargo, cuando el relato pasa a boca de D. José, Carmen será una «hechicera», manteniéndose la anfibología de la palabra: «S'il y a des sorcières, cette fille-là en était une! ${ }^{26}$, como juzga el amante al rememorar su ardoroso proceso de enamoramiento. Aunque es más llamativo que en el proceso fatídico que Carmen enuncia desde los primeros momentos de su relación con D. José, ella misma sea quien se asimile al diablo, como portadora de una maldición para el hombre que, a la postre, acabará con ella misma; para despedir al inexperto muchacho antes de que se haga ninguna ilusión posesiva, Carmen le argumenta: «mon garçon, crois-moi, tu en es quitte à bon compte. Tu as rencontré le diable, oui, le diable; il n'est pas toujours noir, et il ne t'a pas tordu le cou» ${ }^{27}$; del mismo modo, cuando Carmen despliega su juego de tentación sexual entre su marido y D. José, este, tras ser besado furtivamente por ella, le espeta «Tu es le diable», al que ella responde con un escueto «oui» ${ }^{28}$, no matizado en ningún sentido por un narrador, aquí algo tosco. Así, por tanto, es llamativo (y de difícil justificación interna), que

23. En otras novelas, como Manon Lescaut, cuando se habla de «hechizo»o «hechicera» está ausente esta posibilidad de la brujería; se trata del tópico amoroso de que el amor se provoca mediante filtros mágicos.

24. Mérimée, 1990, op. cit., p. 46. También se declarará incrédulo con respecto a la existencia de los bandoleros, sin más razón que «à force d'en entendre parler et de n'en rencontrer jamais». (Íd., p. 31): «oír hablar de ellos y no encontrarlos jamás». (Mérimée, 1990, op. cit., p. 106).

25. Mérimée, 1990, op. cit., p. 48, («era evidente que no se trataba de una medio hechicera», Mérimée, 1997:125).

26. Ibídem, p. 61, («iSi existen hechiceras, esa chica era una de ellas!», Mérimée, 1997, op. cit., p. 142). «Hechicera» es también el apelativo con que un Frollo, fuera de sí por el deseo sexual, moteja a la deseada Esmeralda; acusación que, a la postre, llevará a la muchacha a la horca.

27. Merimée, 1990, op. cit., p. 68, («Hijo mío, créeme, has escapado bien. Encontraste al diablo, sí, al diablo, no siempre es negro y no te ha retorcido el cuello. Estoy vestida de lana, pero no soy cordero»., Mérimée, 1997, op.cit., p. 151).

28. Mérimée, 1990, op. cit., p.77. 
a punto de ser asesinada por D. José, Carmen se ocupe en una actividad mágica con plomo y agua ${ }^{29}$ y salmodie una canción para invocar a doña María de Padilla, supuesta Reina de los Gitanos, lo que sirve para preparar la ambigua y fácil justificación que da D. José cuando la mata, sin conseguir que ella suplique o muestre miedo: «cette femme était un démon» ${ }^{30}$, «esa mujer era un demonio».

De la misma manera, coincide la apreciación del personaje con la del autornarrador cuando D. José se refiere a la gitana vieja que les abre la puerta de la casa vieja de la calle de Candilejo como «vraie servante de Satan», o cuando considera que, tras la pendencia con el oficial al que da muerte, lo han curado con un bebedizo en el que probablemente ambas han mezclado «quelques-unes de ces drogues assoupissantes dont elles ont le secret» ${ }^{31}$.

Por su parte, don José es el que transmite la creencia en la capacidad de las gitanas para hacer sortilegios con la bar lachí o piedra imán: «Faites-en boire à une femme une pincée râpée dans un verre du vin blanc, elle ne resiste plus» ${ }^{32}$. Apreciación que recoge la información dada por Mérimée en el capítulo erudito: «Mais ce qui est pour elles une source de grans profits, c'est la vente des charmes et des philtres amoureux. Non seulement elles tiennent des pattes de crapauds pour fixer les coeurs volages, ou de la poudre de pierre d'aimant pour se faire aimer des insensibles; mais elles font au besoin des conjurations puissantes qui obligent le diable à leur prêter son secours» ${ }^{33}$. La anécdota con que el autor ejemplifica esta cualidad de las gitanas pone de manifiesto su listeza para sacar provecho de la credulidad bobalicona de los payos $^{34}$.

29. También en Nuestra Señora de París se presenta a Esmeralda vinculada a la magia; de hecho, su nombre guarda relación con el saquito que lleva colgado al cuello, adornado con un gran abalorio que imita a una esmeralda y que la muchacha evita que toque Gringoire, porque -le dice- «es un amuleto y podrías romper el hechizo o éste perjudicarte a ti». (Víctor Hugo, op. cit. p. 139). Lo que contiene el saquito es, en realidad, el zapatito que llevaba Esmeralda al ser robada por los gitanos, prueba que servirá para propiciar la anagnórisis del final.

30. Mérimée, 1990, op. cit., p. 94.

31. Mérimée, 1990, op. cit., p. 73.

32. Ibídem, p. 31, («Haga beber a una mujer una pizca de esa piedra rallada en un vaso de vino blanco, y no se le resiste más». Mérimée, 1990, op. cit., p. 138).

33. Mérimée, 1990, op. cit., p. 98, («Pero lo que para ellas es una fuente de grandes beneficios es la venta de encantamientos y filtros amorosos. No solamente guardan patas de sapos para captar los corazones veleidosos, o polvo de piedra imán para hacerse amar de los insensibles, sino que hacen, cuando es necesario, poderosos conjuros que obligan al diablo a prestarles ayuda». Mérimée, 1995, op. cit., p. 186).

34. Quien subraya la condición de gitana y hechicera para su protagonista es Alfonso Sastre en su Tragedia fantástica de la gitana Celestina (1977-1978), a quien vincula con la tierra que le da fuerza frente a los opresores (Sastre, A., Obras completas. Teatro I. Madrid: Aguilar, 1967). 
Estos aspectos temáticos que subrayo vienen a mostrar la cohesión de Carmen en sus diferentes partes y revelan la ligazón que el núcleo ficcional, dramático, del relato de D. José tiene con respecto al capítulo final, erudito, a la par que, por supuesto, van diseñando la figura simple y poderosa de la mujer atractiva y destructora.

Es significativa, a este respecto, la contradicción entre el ensayo y la ficción en cuanto al fatalismo. El autor pinta a los gitanos en su ensayo como descreídos y no supersticiosos (lo que -como decía- les permite sacar provecho de la credulidad de los payos), mientras que hace a Carmen una mujer fatalista. No cabe duda de que este rasgo de la protagonista y este componente del mundo ficcional, son achacables, de forma general, al romanticismo y, en cuanto a la marcha de la trama, a su utilidad para justificar el final dramático: el sino, el fatum, el destino, lo que ya estaba escrito, esa fuerza sobrehumana, ciega y destructiva que arrasa a los amantes, presta a estas obras románticas un nivel metafísico que las adensa y dinamiza ${ }^{35}$. En el caso de Carmen -separándose de otras obras representativas, como Alfredo, Macías o Don Álvaro-, se da la peculiaridad de que el fatum pierde protagonismo y potencia y se vincula más con la pasión sexual que con la amorosa (aunque aquella pueda subyacer a ésta) y, además, de que sea la muchacha la que lo sustente y haga presente en el relato, como un leit-motiv. No es necesario (ni adecuado) vincular Carmen con la tragedia griega o romana ${ }^{36}$, porque el Romanticismo puso en pie su propio mundo, como drama: el fatum o sino no es el destino de los griegos: detrás de aquel no están los dioses, sino un vacío incomprensible y angustioso.

El final, dramático y sangriento, se anticipa por parte de los dos protagonistas. En el caso de don José, su violencia, reprimida a duras penas, en varios momentos, anuncia el estallido final. Carmen es la que pone voz al fatalismo. Pronto le dice a José que le traerá mala suerte (aunque bien es cierto, que lo que está sopesando, sobre todo, es el carácter de don José, al que dice que no sabe hacer «que des bêtises», estupideces ${ }^{37}$; en esta misma línea reacciona a la amena-

35. La Fortuna, el hado, la fatalidad, el destino («cruel», por lo general), son invocados, por supuesto, antes del Romanticismo; pero no con la trascendencia ni funcionalidad con que los contempla este movimiento ideológico y literario. Por ejemplo, en Manon Lescaut (obra publicada en 1733 e indicadora de la crisis de valores tras la muerte de Luis XIV), el Caballero Des Grieux culpa al «ascendiente de mi destino, que me arrastraba a mi perdición» (1984: 78) de su súbita, incendiaria e irreprimible inclinación hacia Manon; se refiere en otro momento a la Fortuna, que «sólo me librará de un precipicio para hacerme caer en otro». (1984: 124), y condensa toda su peripecia en esta otra formulación, más próxima al romanticismo: «Me volvéis a ver tal como me dejasteis hace cuatro meses: igual de enamorado e igual de desgraciado por este amor fatal en el que no me canso de buscar mi felicidad». (1984: 125).

36. Como hacen Luis López Jiménez y Luis-Eduardo López Esteve en la Introducción a Carmen: Mérimée, 1997, op. cit., pp. 52-60.

37. Mérimée, 1990, op. cit., p. 72. 
za de matarla de don José, si no se comporta con él como una verdadera esposa, diciéndole que ya había visto «dans du marc du café que nous devions finir ensemble» ${ }^{38}$; la superstición y creencia en un destino mortal la expresa Carmen con contundencia como respuesta a la siguiente, y ya muy verosímil amenaza de muerte de su amante: «J'ai toujours pensé que tu me tuerais. La première fois que je t'ai vu, je venais de rencontrer un prêtre à la porte de ma maison. Et cette nuit, en sortant de Cordoue, n'as tu rien vu? Un lièvre a traversé le chemin entre les pieds de ton cheval. C'est écrit» ${ }^{39}$.

La cohesión de los dos capítulos introductorios con el tercero, el que contiene la historia pasional de Carmen y José, es más fuerte y de otra índole que la vista entre éste y el final, por cuanto aquellos forman parte del mundo diegético ficcional, son intradiegéticos ${ }^{40}$, y el autor-narrador se incluye a sí mismo como personaje y, a la postre, como confidente de los dramáticos sucesos que se producen en la relación de Carmen y Don José. Si las peripecias de este autor-narrador servían en los primeros pasajes de la novela para presentarlo a los lectores como experimentador directo, como conocedor de los actores principales del drama, y también para hacerse familiar a D. José, es su condición de viajero atento al conocimiento de las peculiaridades del país que visita la que le vale para acceder al relato de D. José.

En efecto, después de ser despedido con tensa cortesía por un furioso D. José, al encontrarlo con Carmen y de notar que la muchacha le ha robado su flamante reloj, el autor-narrador, Mérimée, dice haber estado varios meses vagando por Andalucía y haber entrado en Córdoba de vuelta a Madrid. En el convento de los dominicos, donde estuvo investigando en su primera visita, es animado por uno de los frailes («qui m'avais toujour montré un vif intérêt dans mes recherches sur l'emplacement de Munda» ${ }^{41}$ a que visite a D. José, que aguarda preso a ser ajusticiado. El argumento que el dominico da es -salva la apreciación inhumana del final- el propio de quien encarece las visitas turísticas a un visitante notable que se sabe está seriamente interesado por los usos y costumbres del país que visita:

38. Ibídem., p. 86, («en los posos del café que debíamos acabar nuestros días juntos». Mérimée, 1997, op. cit., p. 122).

39. Mérimée, 1990, op. cit., pp. 90-91, («Siempre he pensado que me matarías. La primera vez que te vi, acababa de encontrar a un cura en la puerta de mi casa. Y esta noche, al salir de Córdoba, ¿no has visto nada? Una liebre ha atravesado el camino entre las patas del caballo. Está escrito». Mérimée, 1990, op. cit.., p. 176).

40. Genette 1972, op. cit. y Nuevo discurso del relato. Madrid, Cátedra, 1998.

41. Mérimée, 1990, op. cit., p. 50, («que había mostrado siempre vivo interés por mis investigaciones sobre el emplazamiento de Munda». Mérimée, 1997, op. cit.). 
«c'est un homme digne à voir, et vous qu' aimez à connaître les singularités du pays, vous ne devez pas négliger d'apprendre comment en Espagne les coquins sortent de ce monde» ${ }^{42}$. Recibido por D. José, ya en capilla, este también valora la índole del viajero al que conoció y al que debió el favor de un trato agradable, alguna vianda y cigarros y el aviso para que pudiera escapar de los lanceros reales; al pronunciar su apellido, Lizarrabengoa, D. José da por supuesto que su oyente deducirá de él que es «vasque et vieux chrétien» ${ }^{43}$, porque «vous connaissez assez l'Espagne» ${ }^{44}$. En los primeros compases del relato que D. José hace a su oyente, el primero tiene en cuenta la condición de foráneo del segundo, haciendo algunas referencias que serían ociosas para un compatriota; así alude a cómo los navarros se olvidan de todo cuando juegan a la pelota, o da por supuesto que si el viajero ha ido a Sevilla conocerá el edificio de la fábrica de tabacos donde comienza su drama, y sabrá también de la índole de las trabajadoras. Y, sin embargo, muy pronto D. José va dejando de lado no sólo la condición foránea de su oyente (que no interlocutor), para quedarse ante un hombre que escucha, sin más, y al que considera capaz de entender su drama; oyente que casi va desapareciendo para dejar la palabra del narrador ante cualquier lector, ganando el relato en inmediatez y en eficacia; de hecho, no van más allá de la decena las expresiones fáticas con que don José se refiere a su silencioso oyente y todas tienden a religar al oyente con el relato y todas presentan la misma fórmula discursiva, con mínimas variantes: «vous saurez, monsieur... ${ }^{45}$, «Le croiriez-vous, monsieur? $\gg^{46}$, «Vous pensez bien que ${ }^{47}$, «Vous le dirai-je, monsieur?» ${ }^{48}$, «Pour le faire court, monsieur $»^{49}$, «Vous vous imaginez le plaisir que me fit cette nouvelle» ${ }^{50}$, «Voila, monsieur, la belle vie que j'ai menée $»^{51}$, «Monsieur, quand cette fille-là riait, il n’y avait pas moyen de parler raison $»^{52}$, «Tous ces détails-là vous ennuient sans

42. Mérimée, 1990, op. cit., p. 51 («es un hombre digno de ver, y usted a quien le gusta conocer las singularidades del país, no debe desaprovechar la ocasión de saber cómo en España los tunantes salen de este mundo»).

43. Mérimée, 1990, op. cit., p. 53.

44. Ibídem, p. 53.

45. Ibídem, p. 54.

46. Ibídem, p. 61.

47. Ibídem, p. 62.

48. Ibídem, p. 73.

49. Ibídem, p. 74.

50. Ibídem, p. 76.

51. Ibídem, p. 77.

52. Ibídem, p. 82. 
doute, mais j’ai bientôt fini» ${ }^{53}$, «Je ne vous parlerai pas de notre dernière entrevue ${ }^{54}$, «Tout, monsieur, tout; je lui offris tout» ${ }^{55}$.

Es interesante notar también que ambos narradores son ajenos al mundo del que relatan, porque si el viajero es francés, D. José subraya su condición de navarro, frente al resto de lo español (esos españoles que juegan cuando están de guardia, frente a él, que como navarro, trata de estar ocupado ${ }^{56}$ ) y, sobre todo, respecto a este mundo de la Andalucía gitana ante el que se siente ajeno (esos «fanfarons Andalous ${ }^{57}$ ) y ante cuyas mujeres se aturde ${ }^{58}$.

Coinciden ambos, autor-narrador y personaje protagonista masculino, en el tópico adverso a los gitanos $\mathrm{y}$, singularmente, es de un cinismo descarado el que D. José, tras asesinar a Carmen, concluya su relato culpando a los gitanos: «Pauvre enfant! Ce sont les Calés qui sont coupables pour l'avoir élevée ainsi» ${ }^{59}$. Lo relevante y sintomático, a este respecto, es que es todo el relato ficcional, y no solo el del asesino, el que concluya con esa apreciación, sin que el autor-narrador tome la palabra para hacer alguna observación o juicio al respecto.

La condición de viajero extranjero del autor-narrador afecta al relato, no sólo en su decantación temática, sino en aspectos de tipo pragmático. La novela se dirige, en principio, a lectores franceses. En los dos primeros capítulos el autornarrador hace algunas referencias para pertrechar de algún modo la enciclopedia de conocimientos de sus compatriotas sobre lo español. Así, comienza por afirmar que en España el compartir tabaco «établit des relations d'hospitalité» ${ }^{60}$ y se declara lo bastante conocedor del carácter español como para saber que los lazos de cortesía que se anudan cuando se comparte tabaco lo mantienen a salvo de cualquier hostilidad del hombre hosco al que acaba de encontrar y que resultará ser el bandolero D. José Navarro, o conocedor de nuestro acervo sapiencial citando un dicho español: «Oeil de bohémien, oeil de loup» («ojo de gitano, ojo de

53. Ibídem, p. 86.

54. Ibídem, p. 89.

55. Ibídem, p. 93.

56. Ibídem, p. 54

57. Ibídem, p. 76.

58. Ibídem., p. 54: «Les Andalouses me faisaient peur».

59. Ibídem, p. 94, («¡Pobrecilla! Los calé son culpables por haberla educado así». Mérimée, 1997. op. cit., p. 181).

60. Mérimée, 1990, op. cit., p. 33; más adelante hará gala de conocer el carácter español: «Je connaissais assez le caractère espagnol pour étre très sûr de n'avoir rien à craindre d'un homme qui abatí mangé et fumé avec moi». (Íd., p. 35). 
lobo»), del que dice «dénote une bonne observation ${ }^{61}$ o referirse a Andalucía como la «Tierra de Jesús» ${ }^{62}$. Este conocimiento no le impedirá patinazos tópicos como el afirmar que en España hay bandurrias por todas partes ${ }^{63} \mathrm{o}$ considerar el gazpacho una ensalada ${ }^{64}$, o hacer que un gitano considere que unas mulas y unas mujeres que aparecen para ser desvalijadas son un regalo de «San Nicolás» ${ }^{65}$.

En suma, la condición de viajero y erudito del autor-narrador del relato de Mérimée afecta a la configuración de Carmen, tanto en aspectos temáticos como pragmáticos, desde la propia elección del tópico del crimen pasional en una Andalucía gitana, bandolera y torera. El texto conjunto de la obra, pese a su heterogeneidad y desequilibrio, funciona como un todo que moviliza la significación y hace más explicables las claves del relato central.

Si el relato de D. José puede adquirir independencia es, en buena medida, porque tiene rasgos formales, temáticos y pragmáticos que lo posibilitan: un narrador propio, una estructura de monólogo con oyente, una actitud confesional y un motivo central propios: el de la relación entre D. José y Carmen; pero también, porque la mirada del colectivo popular del siglo XIX al XXI está guiada por el gusto por lo extrañado y por lo pasional fatídico, mientras que ha tendido a prescindir de componentes como la erudición o el marco del viajero.

Claro es que, sobre estas condiciones, la constitución de la historia de D. José y Carmen como mito de gran fuerza significativa se produce por el acierto de Mérimée en la explotación sobria y potente del tópico de una España castiza gitana, en la que la muerte violenta de la mujer zanjaba los asuntos de honor y celos, revitalizando un machismo sanguinario, celoso y posesivo, campeante bajo la divisa de «la maté porque era mía», que no es más que una variante de la disyuntiva atroz «o mía o muerta». En Carmen no puede siquiera hablarse de «honor», de lavar con sangre una afrenta de ese sentimiento tan poderoso como letal. Este concepto amparador y enmascarador de una ideología machista y violenta, sojuzgadora de

61. Ibídem, p. 47.

62. «Je crois que vous êtes du pays de Jésus, à deux pas du paradis. (J'avais appris cette métaphore, qui désigne l'Andalousie, de mon ami Francisco Sevilla, picador bien connu». (Íd., p. 45).

63. Id. p. 37.

64. Ídem.

65. «Voilà deux mules et deux femmes que saint Nicolas nos envoie» (Mérimée, 1990, op. cit., p. 78; Mérimée, 1997, op. cit., p. 162). Tampoco es muy ajustada la referencia de Víctor Hugo, quien compara a Quasimodo, hostigado por la multitud con "el toro de Asturias que no se inmuta apenas por el puyazo del picador, se irrita por las mordeduras de los perros y por las banderillas.”(Víctor Hugo, op. cit., p. 259). 
la mujer (omnipresente en la literatura del Siglo de Oro español ${ }^{66}$ ) no le alcanza a Don José: más primitivo, sólo entiende el instinto de macho encelado sexualmente por una hembra, cuya libertad no entiende ni admite ni respeta; el caso de don José se aproxima más, en este primitivismo, al deseo de venganza sangrienta de Tamar, en el Auto de Tamar (del Códice de Autos Viejos), cuando es violada por su hermano, Amón ${ }^{67}$, que a Otelo o A secreto agravio, secreta venganza, por ejemplo.

En este primitivismo y yendo más lejos, enlaza Carmen con los mitos poderosos de la mujer maléfica ${ }^{68}$, que puede rastrearse, con mayor o menor deuda por parte de Carmen, desde los mitemas de la vagina dentada (incapacidad de don José de resistirse a la sexualidad de Carmen y el temor que siente ante ella), siguiendo con los numerosos mitos griegos de Pandora (que desata todos los males ${ }^{69}$ ), las sirenas (la risa irresistible de Carmen) o de Venus (Carmen saliendo de las aguas del Guadalquivir), Diana cazadora (Carmen vengándose de quien la ha visto en el baño), Circe (la engañadora), o la voraz e insaciable Caribdis; leyendas bíblicas como la de Judith y Holofernes o Sansón y Dalila, o Juan el Bautista y Salomé. De manera explícita, con doctrina adversa a la mujer, se expresan libros sagrados tan representativos como la Biblia ${ }^{70}$

66. Recuérdese que Lope, en su Arte nuevo de hacer comedias, dirigido a la Academia de Madrid, se refería a los casos de honra como los «mejores», «porque mueven con fuerza a toda gente». (Vega, Lope de, Arte nuevo de hacer comedias, ed. Ma Grazia Profeti. Nápoles: Liguori, 1999).

67. ¡O quién te tomase, Amón,

y de tu sangre se hartase,

siquiera porque vengase

bien vengado el coraçón

y mi rabia se acabase! (Auto de Tamar, ed. Mercedes de los Reyes Peña, «El Aucto de Tamar del Ms. B2476 de la Biblioteca de The Hispanic Society of America: estudio y edición», Criticón, 66-67 (1996), pp. 383-414, vv. 210-214).

68. Durand, G., Las estructuras antropológicas del Imaginario. Introducción a la Arquetipología general. Barcelona: Taurus, 1982.

69. Ver Carlos García Gual, «Mitología griega», en A. Bernabé y otros, Mitología y religión del Oriente Antiguo. III. Indoeuropeos. Obra colectiva editada por Gregorio del Olmo Lete, Sabadell, Ausa, 1998, pp. 167-168.

70. En la primera carta de San Pablo a Timoteo, se lee: «Por lo que a las mujeres se refiere, que vayan vestidas decorosamente, que se presenten con recato y modestia; que su adorno no sean los cabellos rizados, joyas de oro, perlas o vestidos suntuosos, sino las buenas obras, como conviene a las mujeres creyentes. Que la mujer aprenda sin protestar y con gran respeto. No consiento que la mujer enseñe ni domine al marido, sino que debe comportarse con discreción. Pues primero fue formado Adán y después Eva. Y no fue Adán el que se dejó engañar, sino la mujer que, seducida, incurrió en la transgresión. Se salvará, sin embargo, por su condición de madre, siempre que persevere con modestia en la fe, el amor y la santidad». (La Biblia. Traducción totalmente revisada con amplias notas e introducciones. Edición aprobada por la Conferencia Episcopal Española, Madrid, Atenas, PPC, Sígueme, Verbo Divino, 1992, p. 1806. 
o El Corán, y en textos literarios fundamentales para sus culturas, como los Edda ${ }^{71}$.

La consideración adversa y peyorativa del autor contra Carmen -y por extensión, contra la mujer (misoginia que se observa también en otras obras suyas- se exhibe como una divisa en la cita en exergo de Páladas con la que se abre el libro: «Toda mujer es hiel. Pero tiene dos momentos buenos; uno en el tálamo; el otro, al morir».

Carmen es una obra monológica ${ }^{72}$. En ella son los hombres los que dominan la información. No tenemos la versión de Carmen de la historia, sólo las del autornarrador y la de don José; sólo la voz de Carmen en los diálogos permite al lector aproximarse al interior de la muchacha. Su declaración propia más relevante es la que hace a un don José agobiante y posesivo: «Je ne veux pas étre tourmentée ni surtout commandé. Ce que je veux, c'est étre libre et faire ce qui me plaît. Prends garde de me pousser à bout» ${ }^{73}$; deseo vehemente de libertad que habría que poner en relación con el gran valor dado por los gitanos a su independencia, como se dice tanto en La gitanilla como en Carmen: «Comme mon rom, tu a le droit de tuer ta romi; mais Carmen sera toujours libre» ${ }^{74}$.

Por ello, por esta mirada masculina (que, en ocasiones, es compartida también por algunos comentaristas), se traduce el atractivo de Carmen como un poder diabólico o maléfico y el estado de don José como el de un hechizado, cuando se trata, tan sólo, de sexualidad, de la desinhibida de Carmen y, por supuesto, de la inmadura y reprimida de don José, que afecta también al carácter: «C'était plus forte que moi»., «J'étais si faible devant cette créature que je obéissais à tous ses caprices» ${ }^{75}$, declara al narrador-viajero. Quizá por esto, la otra figura femenina que aparece en la novela

Y en El Corán, 4/38: «Los hombres están por encima de las mujeres, porque Dios ha favorecido a unos respecto de otros y porque ellos gastan parte de sus riquezas en favor de las mujeres. Las mujeres piadosas son sumisas a las disposiciones de Dios; son reservadas en ausencia de sus maridos en lo que Dios mandó ser reservado. A aquéllas de quienes temáis la desobediencia, amonestadlas, confinadlas en sus habitaciones, golpeadlas». (El Corán. Traducción, introducción y notas de Juan Vernet (catedrático de lengua árabe de la Universidad de Barcelona), Barcelona: Planeta, 1963, p. 85.

71. «Que nadie confíe en palabras de moza/ ni en nada que diga mujer:/ corazón se les dio - ison ellas volubles $;-/$ moldeado en la rápida rueda». (Edda Mayor. Traducción del islandés y edición de Luis Lerate. Madrid: Alianza Editorial, 2000, p. 48).

72. M. Bajtín, Teoría y estética de la novela (Trabajos de investigación). Madrid, Taurus, 1989.

73. Mérimée, 1990, op. cit., p. 87; «No quiero ser atormentada ni, sobre todo, mandada. Lo que quiero es ser libre y hacer lo que me place. Líbrate de agotarme la paciencia». Mérimée, 1997, op. cit., p. 172.

74. Mérimée, op. cit., p. 93.

75. Ibídem, p. 75. 
es la de la mujer sumisa y entregada a un amante tiránico. Se trata de la pareja formada por José María el Tempranillo, el célebre bandolero, y su amante, de la que cuenta cómo un día él le asestó un navajazo y ella lo tomó como muestra de amor, mostrando la cicatriz como «la plus belle chose du monde». Don José, al comentar este caso, sentencia: «Les femmes sont ainsi faites, les Andalouses surtout» ${ }^{76}$.

El orden externo del hombre (las tradiciones de su tierra, su sentido del deber, su condición de militar, cubren con precariedad un desorden tumultuoso en su interior: su condición irascible y violenta, que se desata y dispara al contacto con la libertad sin complejos de Carmen. Como apunté más arriba, don José (que ha debido dejar su tierra por una pelea con bastones), reprime varias veces con dificultad sus impulsos y deseos violentos y homicidas con respecto a Carmen: la primera, cuando él va a cobrarse el favor que ha hecho a Carmen dejando pasar a sus amigos contrabadistas ${ }^{77}$; la segunda por la forma de hablar de ella ante sus celos ${ }^{78}$; la tercera cuando la encuentra tan feliz en Gibraltar en casa de un inglés ${ }^{79}$; la cuarta ya es una amenaza seria: la profiere don José a Carmen advirtiéndole de que la matará si no es con él una verdadera romí, esposa ${ }^{80}$; la quinta es ya una agresión: don José golpea a Carmen, tras una disputa violenta porque la muchacha acaba de robar el reloj del narrador-viajero y quiere robarle también un anillo (incluso matarlo) ${ }^{81}$; la sexta es una amenaza de muerte cargada de credibilidad: Carmen no accede a ir con José a América, ni prometerle fidelidad, y él sólo ve como solución matarla ${ }^{82}$.

El resultado del relato de don José, sin embargo, no es una valoración ecuánime de los errores cometidos en la relación. Bien al contrario, la muerte de Carmen la justifica como el castigo al crimen de haber corrompido a un buen hom-

76. Ibídem, p. 79.

77. «Peu s'en fallut que je ne lui jetasse la pièce à la tête, et je fus obligé de faire un effort violent sur moi-même pour ne pas la battre». (Ibídem, p. 70), («Faltó poco para que no le tirara la moneda a la cara y me vi obligado a hacer un violento esfuerzo sobre mí mismo para no golpearla». Mérimée, 1997, op. cit., p. 154).

78. «Lorsqu'elle parlait ainsi, j'avais envie de l' étrangler». (Mérimée, 1990, op. cit., p. 74), «Me daban deseos de estrangularla cuando hablaba así». (Mérimée, 1997, op. cit., p. 158).

79. «Et toi -le dis-je dans ma langue- tu as l'air d'une effrontée coquine et j'ai bien envie de te balafrer la figure devant ton galant». (Mérimée, 1990, op. cit., p. 81), («Y tú -le dije en mi lengua- tienes aspecto de una tunanta desvergonzada y me dan unas ganas enormes de rajarte la cara delante de tu galán». (Mérimée, 1997, op. cit., p. 166).

80. «Et le tien [temps], si tu n'es pas pour moi une vraie romi». Mérimée, 1990, op. cit., p. 93), «Y el tuyo, si no eres para mí una verdadera esposa». (Mérimée, 1997, op. cit., p. 171).

81. «Nous eûmes une violente dispute, et je la frappait». (Mérimée, 1990, op. cit., p. 89).

82. «Je suis las de tuer tous tes amants; c'est toi qui je tuerai». (Mérimée, 1990, op. cit., p. 90), («Estoy cansado de matar a todos tus amantes; te mataré a ti». (Mérimée, 1997, op. cit., p. 176). 
bre, con la explicitación del tópico del que se pierde por una mujer: «c'est toi qui m'as perdu; c'est pour toi que je suis devenu un voleur et un meurtrier. Carmen! ma Carmen!, laisse-moi te sauver et me sauver avec toi ${ }^{83}$.

Esta visión sobre la mujer que ofrece Mérimée en Carmen rebrota constantemente en el arte hasta la actualidad, de forma más o menos explícita, como puede comprobarse con un somero acercamiento a la historia del cine (con la figura tópica de la femme fatale o la vamp, en películas "míticas" como Perdición, de Wilder o Gilda, de Vidor), o de la literatura. Por traer a colación algunos ejemplos y diferentes facetas de esta visión del mundo, puede verse cómo en el relato «Clone», de Cortázar se reproduce y justifica la misma actitud violenta que en Carmen:

Todo parece girar en torno a Gesualdo, si tenía derecho a hacer lo que hizo, o si se vengó en su mujer de algo que hubiera debido vengar en sí mismo. Entre dos ensayos, bajando al bar del hotel para descansar un rato, Paola discute con Lucho y Roberto, los otros juegan canasta o suben a sus habitaciones. Tuvo razón, se obstina Roberto, entonces y ahora es lo mismo, su mujer lo engañaba y él la mató, un tango más, Paolita. Tu grilla de macho, dice Paola, los tangos, claro, pero ahora hay mujeres que también componen tangos y ya no se canta siempre la misma cosa. Habría que buscar más adentro, insinúa Lucho, el tímido, no es tan fácil saber por qué se traiciona y por qué se mata. En Chile puede ser, dice Roberto, ustedes son tan refinados, pero nosotros los riojanos, meta facón nomás ${ }^{84}$.

En La mujer del teniente francés, de John Fowles, su protagonista masculino se remonta a las figuras míticas y arquetípicas de la Mujer Terrible. Cuando Charles, rotos sus compromisos de matrimonio con Ernestina y con ellos su honorabilidad, hace el amor con la enigmática Sara, la Trágica, "la mujer del teniente francés", como la llaman con desprecio los habitantes de Lyme, descubre estupefacto que la muchacha es virgen y sus elucubraciones se disparan:

Ella no se había entregado a Varguennes. Le había mentido. Su conducta, todo lo que le había contado en Lyme Regis era mentira. Pero ¿por qué? ¿por qué? ¿por qué?

Porque quería coaccionarle.

¡Tenerle en su poder!

Y todas las diablesas que envenenan la mente de los hombres engendrando en ella el temor de ser víctimas de una tremenda conspiración femenina, urdida para chu-

83. Mérimée, 1990, op. cit., p. 93 («eres tú quien me ha perdido; es por ti por quien me he convertido en ladrón y homicida. ¡Carmen! ¡Carmen mía! Déjame salvarte y salvarme contigo»., Mérimée, 1990, op. cit., p. 180).

84. Julio Cortázar, «Clone», en Obras completas. I. Cuentos. Edición e introducción general de Saúl Yurkevich. Con la colaboración de Gladis Anchieri. Prólogo de Jaime Alazraki, Barcelona, Círculo de Lectores, Galaxia Gutemberg, 2003, p. 949. 
parles la virilidad de las venas, desposeerles de su idealismo, para fundirlos como cera y moldearlos después a su infame capricho... ${ }^{85}$.

Todavía es más acusada esta enrevesada misoginia en la obra de Daphne du Maurier, Rebecca, donde la independencia sexual de la mujer y su desprecio altivo por todo lazo de afecto y norma convencional es considerada como cínica e inmoral por Maximiliano de Winter, su esposo ${ }^{86}$, quien sólo encuentra como solución su asesinato; acción que justifica por el temor al escándalo y que se produce al creer que Rebecca está embarazada de otro hombre. Este perfil amenazador de Rebecca resalta más al ser comparada con la inmadura, tímida, sumisa y siempre dispuesta a agradar, segunda esposa, que elude cualquier referencia sexual en su relato, y se pliega con devoción a restañar las heridas de su marido. Es esta muchacha, sin embargo, la que muestra la imagen de Rebecca con rasgos más poderosos y menos negativos, como mujer «dispuesta a apurar la copa de la vida», como «triunfadora» ${ }^{87}$.

\section{Bibliografía}

Auto de Tamar, ed. Mercedes de los Reyes Peña, «El Aucto de Tamar del Ms. B2476 de la Biblioteca de The Hispanic Society of America: estudio y edición», Criticón, 66-67 (1996), pp. 383-414, vv. 210-214).

BAJTÍN, M., Teoría y estética de la novela (Trabajos de investigación). Madrid, Taurus, 1989.

85. John Fowles, La mujer del teniente francés, Barcelona: Orbis, 1987, p. 362. Muy cerca de esta apreciación está la que hace el personaje de «Final del juego», de Cortázar: «De la sábana que apenas te cubría alcanzo a entrever la ráfaga instantánea que surca el aire para perderse en la sombra, y ahora estamos desnudos, el amanecer nos envuelve y reconcilia en una sola materia temblorosa, pero te obstinas en luchar, encogiéndote, lanzando los brazos por sobre mi cabeza, abriendo como en un relámpago los muslos para volver a cerrar sus tenazas monstruosas que quisieran separarme de mí mismo». (Julio Cortázar, «Final del juego», en Obras completas. I. Cuentos. Edición e introducción general de Saúl Yurkevich. Con la colaboración de Gladis Anchieri. Prólogo de Jaime Alazraki, Barcelona, Círculo de Lectores, Galaxia Gutemberg, 2003, p. 401).

86. «¿Crees que yo estaba enamorado de Rebecca? ¿Crees que la maté porque la quería? La odiaba, te digo que la odiaba. Nuestro matrimonio fue una farsa desde el primer momento. Rebecca era un ser vicioso, corrompido, despreciable en todos los sentidos, absolutamente todos». (Daphne du Maurier, Rebecca, Barcelona: Círculo de Lectores, 2009, p. 340).

87. Punto de vista muy distinto -aunque no por ello menos complejo- es el que se da en Fiesta, la novela de Hemingway, donde la vida en común de los protagonistas es imposible:

«- ¿No podríamos vivir juntos, Brett? ¿Solamente vivir juntos?

- No, no lo creo. Te engañaría con todo el mundo. No podrías resistirlo.

- Lo resisto ahora.

- Sería diferente. Es culpa mía, Jake. Es mi manera de ser». (Erns Hemingway, Fiesta, Barcelona: Debolsillo, 2007, p. 82. 
BENAVENTE, Jacinto, Lo cursi, en Obras completas, I, Madrid, Aguilar, 1969. BRETÓN DE LOS HERREROS, M., «Un francés en Cartagena», en Teatro Bre$v e$, vol. II. Estudio introductorio y edición de Miguel Ángel Muro. Logroño: Universidad de La Rioja, 2000.

CANET, José Luis, «Lope de Rueda y el teatro profano», en Historia del teatro español I. De la Edad Media a los Siglos de Oro. Javier Huerta Calvo (Director). Abraham Madroñal Duran y Héctor Urzáiz Tortajada (coord.), 2003, pp. 431-474.

CERVANTES, Miguel de, La gitanilla. La ilustre fregona, Madrid, Espasa-Calpe, 2003. CORTÁZAR, J., «Final del juego», en Obras completas. I. Cuentos. Edición e introducción general de Saúl Yurkevich. Con la colaboración de Gladis Anchieri. Prólogo de Jaime Alazraki, Barcelona: Círculo de Lectores, Galaxia Gutemberg, 2003.

DURAND, G., Las estructuras antropológicas de lo imaginario. Madrid, Taurus, 1981 (Trad. de Les estructures anthropologiques de l'imaginaire. Paris, P.U.F., 1964).

Edda Mayor. Traducción del islandés y edición de Luis Lerate. Madrid: Alianza Editorial, 2000.

El Corán. Traducción, introducción y notas de Juan Vernet (catedrático de lengua árabe de la Universidad de Barcelona). Barcelona: Planeta, 1963.

FOWLES, J., La mujer del teniente francés. Barcelona: Orbis, 1987.

GARCÍA LANDA, J.A., Acción, relato, discurso. Estructura de la ficción narrativa. Salamanca: Ediciones Universidad de Salamanca, 1998.

GARCÍA PEINADO, M.A., Hacia una teoría general de la novela. Madrid, Arco Libros, 1998.

GENETTE, G., Nuevo discurso del relato. Madrid: Cátedra, 1998 (1ª ed. 1983).

GENETTE, G., «Fronteras del relato», en VV. AA., Análisis estructural de los relatos. Buenos Aires: Tiempo Contemporáneo, 1970, pp. 193-208. («Introduction à l'analyse structurale des récits»,Communications, 8, 1966). («Frontières du récit», Figures II. Seuil, Paris, 1966, pp.49-69).

GENETTE, G., Figures III. Paris: Seuil, 1972.

GREIMAS, A.J., Semantique structurale: recherche de méthode. Paris: Larousse, 1966.

GREIMAS, A.J., Du sens. Essais sémiotiques. Paris: Seuil, 1970a (trad. española En torno al sentido. Ensayos semióticos. Madrid: Fragua, 1973).

GREIMAS, A.J., «Elementos para una teoría de la interpretación del relato mítico»., en VV.AA., Análisis estructural del relato. Buenos Aires: Tiempo Contemporáneo, 1970b, pp. 45-86.

GREIMAS, A.J., Semántica estructural. Investigación metodológica. Madrid: Gredos, 1971.

GREIMAS, A.J., «Elementos de una gramática narrativa», en Greimas, 1973, pp. 185-217. 
GREIMAS, A.J. y RASTIER, F., «Las reglas del juego semiótico», en Greimas, 1976, pp. 153-183.

GREIMAS, A.J., «Pour une théorie des modalités», Langages, 34, 1976; pp. 90102 (trad. esp.: «Para una teoría de las modalidades», en Greimas, 1989, pp. 78-105).

GREIMAS, A.J., «Hacia una teoría del discurso poético», en Greimas, A.J. $y$ otros : Ensayos de semiótica poética. Conjunto dirigido por A.J.Greimas. Barcelona, Planeta, 1976.

GREIMAS, A.J. y otros, Ensayos de semiótica poética. Conjunto dirigido por A.J.Greimas. Barcelona: Planeta, 1976.

GREIMAS, A.J. y COURTES, J., Semiótica. Diccionario razonado de la teoría del lenguaje. Tomo I. Madrid: Gredos, 1982.

GREIMAS, A.J., La semiótica del texto. Ejercicios prácticos. Barcelona: Paidós, 1983.

GREIMAS, A.J., Semiótica. Diccionario razonado de la teoría del lenguaje. Tomo II. Madrid: Gredos, 1991.

GREIMAS, A.J., En torno al sentido. II. Ensayos semióticos. Madrid: Gredos, 1989.

GREIMAS, A.J., «Los actantes, los actores y las figuras», en Greimas 1989, pp. 57-78.

HEMINGWAY, E., Fiesta, Barcelona: Debolsillo, 2007.

HEGEL, G.W.F, Lecciones de estética. Traducción del alemán de Raúl Gabás. Barcelona: Península, 1989.

HUGO, V., Nuestra Señora de París. Edición de Eloy González Miguel. Traducción de María Amor Hoyos Ruiz y Eloy González Miguel, Madrid: Cátedra, 1985.

La Biblia. Traducción totalmente revisada con amplias notas e introducciones. Edición aprobada por la Conferencia Episcopal Española, Madrid, Atenas: PPC, Sígueme, Verbo Divino, 1992.

LANSER, S., The narrative act. Point of view in fiction. Princeton: Princeton U.Press, 1981.

MAURIER, D. du, Rebecca, Barcelona: Círculo de Lectores, 2009.

MÉRIMÉE, P., Carmen et autres histories d'Espagne. Preface et commentaires de Pascaline MOURIER-CASILE, Pocket, 1990.

MÉRIMÉE, P., Carmen. Edición de Luis López Jiménez y Luis-Eduardo López Esteve. Madrid: Cátedra, 1997.

MURO, M.A., Análisis e interpretación del cómic. Ensayo de metodología semiótica. Logroño: Universidad de La Rioja, 2004.

PREVOST, Historia del caballero Des Grieux y de Manon Lescaut, Edición de Javier del Prado, traducción de Susana Cantero. Madrid: Cátedra, 1984.

RANK, Otto, El mito del nacimiento del héroe, Barcelona, Paidós, 1981. 
RIMMON KENAN, S., «A Comprehensive Theory of Narrative: Genette's Figures III and the structuralist study of fiction», Poetics and Theory of Literature, I, 1976, pp. 33-62.

RIMMON KENAN, S., Narrative Fiction: Contemporary Poetics. New York: Methuen, 1983.

SÁNCHEZ SALAS, D., Historias de luz y papel. El cine español de los años veinte, a través de su adaptación de narrativa literaria española. Murcia, Filmoteca Regional, 2007.

SASTRE, A., Obras completas. Teatro I. Madrid: Aguilar, 1967.

TOMASEVSKI, B., «Temática», en L.T. Lemon y M. Reis, Russian Formalist Criticism, Lincoln: University of Nebraska Press, 1965, pp., 61-95.

TOMASEVSKI, B., Teoría de la literatura. Madrid, Akal, 1982. (Trad. de Teorija literatury Poetika. Leningrado, 1925).

UBERSFELD, A., Semiótica teatral. Madrid: Cátedra-Universidad de Murcia, 1993.

VEGA, Lope de, Arte nuevo de hacer comedias, ed. Ma Grazia Profeti. Nápoles: Liguori, 1999. 